\title{
RELATIONSHIP BETWEEN WOMEN'S BODY DISSATISFACTION, SENSE OF COHERENCE AND PHYSICAL ACTIVITY
}

\author{
Audronė Dumčienė ${ }^{1}$, Jolanta Gedvilienè2, Vaidas Mickevičius ${ }^{3}$ \\ Lithuanian Sports University', Kaunas, Lithuania \\ Mykolas Romeris University², Vilnius, Lithuania \\ Kaunas University of Applied Engineering Sciences ${ }^{3}$, Kaunas, Lithuania
}

\begin{abstract}
Background. Socio-cultural pressure exerted by the environment and the media makes the majority of women take care of their bodies. That is especially true in Western culture which promotes slimmer women in recent decades.

Methods. Two questionnaires were used in this research: Body Shape Questionnaire and Sense of Coherence scale. Research participants were 79 women aged $34.6 \pm 3.76$ years.

Results. After six months of regular fitness classes women's satisfaction of their body and their sense coherence level improved significantly. Relations between body shape dissatisfaction and sense of coherence, body shape dissatisfaction and manageability, comprehensibility and manageability were found.

Conclusions. Systematic fitness training positively affects women's satisfaction with their body. Understanding of the capability of controlling their body shape was improved. There was a significant relationship between dissatisfaction with their body shape and sense of coherence. The effect of physical activity improved the values of all three components of the sense of coherence construct. The values of comprehensibility, meaningfulness and manageability indicators show that respondents may already have a better control of their sense of coherence.
\end{abstract}

Keywords: women, body shape dissatisfaction, sense of coherence, physical activity.

\section{INTRODUCTION}

I $\mathrm{t}$ is believed that satisfaction with one's own body causes positive emotions, positive approach to the body, and body dissatisfaction, vice versa, causes negative emotions, negative attitudes to the body (Dittmar, 2009).

Inadequate assessment of the body can occur due to both the body weight and the body shape, but it is often associated with the increasing dissatisfaction with the body (Greenleaf, 2005). Persons dissatisfied with their body shape have to take some steps to change their attitudes (McPherson \& Turnbull, 2005).

It can be assumed that satisfaction or dissatisfaction with their bodies is more related to culture rather than body mass. It has been established (McPherson \& Turnbull, 2005) that the overweight men of low socioeconomic status were satisfied with their body weight and body shape and were not likely to change their body weight. However, it was revealed that both men and women were similarly unhappy about their bodies, but women often did something about that while men did not anything (Greenleaf, 2005; McPherson \& Turnbull, 2005).

The image of a woman in the media and even normal body composition can make a woman feel dissatisfied with her body. As a result of the influence of media, more and more girls and women seek to be slim as a possibility to escape from sadness, loneliness and failures (Paxton, 2007).

Research results show that 30 to $50 \%$ of women are dissatisfied with their bodies (Pasha \& 
Golshekoh, 2009). Researchers (Brown \& Dittmar, 2005; Dohnt \& Tiggemann, 2006) suggest that dissatisfaction with one's body might be associated with many factors - fashion, peers, media, and family influence. Studies have revealed that body dissatisfaction is associated with poorer physical health, smoking, and poorer psychological wellbeing (Bergeron \& Tylka, 2007; Ganem, Heer, \& Morera, 2009; Meland, Haugland, \& Breidablik, 2007; Pomerleau \& Saules, 2007).

Šivert and Sinanovic's (2008) study shows that younger women were more dissatisfied with their bodies than the older. Researchers believe that older women are in a better position than the younger ones because at their times body ideals were more realistic, they were easier to achieve.

Body dissatisfaction is associated with inadequate self-esteem, anxiety for social assessment (Gianini \& Smith, 2008; Presnell, Bearman, \& Madeley, 2007), depression, and worsening quality of life (Benas \& Gibb, 2007). It has been established (Gilbert-Diamond, Bayle, Mora- Plazas, \& Villamor, 2009) that body dissatisfaction is related to the body mass index - increasing body mass index increases body dissatisfaction. Engeln-Maddox (2005) investigated the influence of the media and found that advertising skinny women on TV increased body dissatisfaction among other women.

Choate (2005) has identified five factors that contribute to the formation of people's satisfaction with their bodies: family support, satisfaction of the sex role, positive assessment of physical condition, effective coping strategies, holistic balance and the sense of wellness. Body dissatisfaction has a negative impact on psychological well-being, the level of stress, anxiety, depression, life satisfaction and self-esteem in both girls and boys (Bergeron \& Tylka, 2007; Bookwala \& Boyar, 2008; Ganem, Heer, \& Morena, 2009; Sujoldzic \& De Lucia, 2007).

Physical activity is associated with body satisfaction. People start exercising to increase their body satisfaction thinking that it can help them to adapt more in the community. Others who are afraid to show their bodies in public can exercise less. It has been shown that physical activity is associated with body satisfaction (Greenleaf, 2005).

Studies have shown that among overweight girls and girls without it physical activity difference is statistically significant. Girls with overweight were more intensely active physically, but for a short time, and those without overweight were constantly active or inactive (Fonseca \& De Matos, 2005).
According Antanovsky's (1987) salutogenic theory, every human has the generalized resistance resources, which, if necessary, help to deal with the difficulties of life. The volume of these resources is associated with personal qualities, intellect, and the provisions of the phenomenon of life, behavior and perception of reasoning, problem-solving strategies, financial capacity, social and cultural factors, enabling to control a stressful situation. The possibilities to use the general resistance resources depend on the person's sense of coherence level. Antanovsky (1987) proposed a scale Sense of Coherence (SOC) for the assessment of the sense of coherence level, which is widely used to search for coherence links with human health, well-being, mental health and other characteristics. Reviews of research on SOC concluded that significance of this relation was confirmed many times (Eriksson \& Lindström, 2006, 2007).

The scale SOC is strongly and negatively associated with anxiety, anger, burnout, demoralization, hostility, hopelessness, perceived depression, perceived stressors, and post-traumatic stress disorder (Bothmer \& Fridlund, 2003; Eriksson \& Lindström, 2005; Skirka, 2000; )

SOC scale can serve for the prediction of staff burnout syndrome (Kalimo, Pahkin, Mutanen, \& Topipinen-Tanner, 2003). According to the survey (Javtokas, 2001), 39.9\% of Lithuanian population demonstrate a high sense of coherence level, while $60.1 \%$ - low.

\section{METHODS}

Research Participants. Research participants started attending regularly fitness classes twice a week in 2013-2014, and not less than half a year they attended group fitness classes. Research included 79 women aged $34.6 \pm 3.76$ years, their mean body mass index was $26.56 \pm 2.84$. All respondents participated in the survey voluntarily; they were informed about the purpose of the study and the anonymity. There were two questionnaires used for data collection - one for the assessment of the body shape and the second one - for the sense of coherence. The study participants' survey was carried out twice: the first one on admission to the fitness group and the second one was conducted after six months. Those who missed more than $15 \%$ of classes were not interviewed for the second time.

The Body Shape Questionnaire (Cooper, Taylor, Cooper, \& Fairburn, 1986) was used for the assessment of women's dissatisfaction with their 
body shapes. The questionnaire consisted of 38 items. The items were rated using a 6-point Likert scale, with response options of $1=$ never, $2=$ rarely, $3=$ sometimes, $4=$ often, $5=$ very often, $6=$ always . Replies estimates were summed. Higher total estimate indicated greater body dissatisfaction.

The scale was adapted for the use with Lithuanian populations using the back-translation procedure described by Hambleton, Merenda and Spielberger (2005).

Questionnaire translation from English into Lithuanian language and back was performed by two professional translators, both of whom had previous experience in adapting research instruments. One of them separately translated the original scale from English to Lithuanian and the second one translated from Lithuanian to English. The backtranslated version and the original version were compared, and no lack of equivalence was found. Then the factor structure of the scale was examined using exploratory factor analysis. We performed a principal components factor analysis with orthogonal (varimax) rotation and Kaiser Normalization. Five factors with eigenvalues greater than 1.00 and item loadings greater than 0.45 for each factor emerged. These factors accounted for $61.72 \%$ of the total variance (Kaiser-Meyer-Olsen $=.81, p<.001$ ). The scale and component factors of the Lithuanian version scale corresponded to the original version of the scale. Estimation of the Cronbach's alpha demonstrated good levels of internal reliability for consistency scale (.918). The reliability estimated by questionnaire authors was .930 (Cooper, Taylor, Cooper \& Fairburn, 1986).

The following factors were identified: ashamed of their body (ten items), fear to become fat (eighth items), dissatisfaction with body shape compared with other women (eighth items), efforts to change the body shape (five items) and negative emotions about the body shape (seven items). The estimation of the Cronbach's alpha demonstrated good levels of internal reliability, consistency for all five subscales $(.938, .878, .901, .882$ and .837$)$.

For the assessment of the sense of coherence level we used Antonovsky (1987) 13 items scale. The scale distinguished three subscales: comprehensibility (cognitive component of the sense of coherence) (five items), meaningfulness (the motivational component of the sense of coherence) (four items) and manageability (the behavioural component of the sense of coherence) (four items). The items are rated using semantic difference 7-point
Likert scales (bad-good), with response options from $1=$ very rarely or never to $7=$ always.

Some items had different response options (e.g. item number four, 1 - did not have completely clear goals and objectives and 7 - had clear goals and targets). While calculating estimates to certify the total values for five items (numbers 1, 2, 3, 7, 10) we needed to decode estimates of the 1-7 scale to 7-1 scale). Reply values were summed (Eriksson \& Lindstrom, 2005), or calculated as averages of values. The total value of SOC-13 scale can be from 13 to 91 . The rating was as follows: more points a higher level of internal sense of coherence. The Lithuanian version of SOC-13 scale was prepared by Javtokas (2009).

Data Analysis. The analysis was performed using SPSS for Windows software (version 19.0). The methods of analysis included factor analysis, Cronbach's alpha coefficients, descriptive statistics, Pearson's correlations, and Student's $t$-test. Statistical significance was set at $p<.05$ for all tests.

\section{RESULTS}

Women's estimates of body dissatisfaction during the first and second surveys are presented in Table 1.

Data on the levels of internal sense of coherence of the respondents are presented in Table 2.

Correlation coefficients between the factors are presented in Table 3.

\section{DISCUSSION}

Based on the results given in Table 1, it can be said that physical activity (participation in regular fitness classes) has favourable influence on women's body satisfaction. The biggest change occurred with the estimates of the item "Dissatisfaction with the body shape compared with other women" (5.6 points) and the item "Negative emotions about the body shape" (5.22 points), and the smallest changes were observed in the item "Efforts to change the body shape" (3.06 points). It can be assumed that women realized their potential to improve satisfaction with their body shape. McLaren \& Kuh's (2004) study showed that over $50 \%$ of normal weight $(\mathrm{BMI}<25)$ women were dissatisfied with their body and women of higher social class were very unhappy about it. Women who smoked were more dissatisfied with their bodies than non-smokers (Pomerleau \& Saules, 2007). Body dissatisfaction is associated and with other factors, 
Table 1. Estimates of women's body dissatisfaction

\begin{tabular}{|l|l|l|l|l|}
\hline \multicolumn{1}{|c|}{ Body dissatisfaction (factors) } & $\begin{array}{c}\text { First testing } \\
\text { Mean } \pm \boldsymbol{S D}\end{array}$ & $\begin{array}{c}\text { Second testing } \\
\text { Mean } \pm \boldsymbol{S D}\end{array}$ & $\boldsymbol{t}$-test & \multicolumn{1}{c|}{$\boldsymbol{p}$} \\
\hline Ashamed of their body shape & $37.67 \pm 6.76$ & $33.43 \pm 4.92$ & 4.51 & $<.0001$ \\
\hline Fear to be heavier & $27.56 \pm 4.93$ & $22.78 \pm 2.98$ & 7.38 & $<.0001$ \\
\hline $\begin{array}{l}\text { Dissatisfaction with body shape } \\
\text { compared with other women }\end{array}$ & $23.49 \pm 2.84$ & $17.89 \pm 2.21$ & 13.83 & $<.0001$ \\
\hline Efforts to change their body shape & $19.35 \pm 2.92$ & $16.29 \pm 2.12$ & 7.54 & $<.0001$ \\
\hline Negative emotions about the body shape & $20.11 \pm 2.08$ & $14.89 \pm 1.96$ & 16.23 & $<.0001$ \\
\hline Total sum of mean values & $128.36 \pm 3.91$ & $104.56 \pm 2.84$ & 43.77 & $<.0001$ \\
\hline
\end{tabular}

Table 2. Levels of internal sense of coherence during the first and the second survey

\begin{tabular}{|l|c|c|c|c|}
\hline \multicolumn{1}{|c|}{ Inner sense of coherence (factors) } & $\begin{array}{c}\text { First survey } \\
\text { Mean } \pm \boldsymbol{S D}\end{array}$ & $\begin{array}{c}\text { Second survey } \\
\text { Mean } \pm \boldsymbol{S D}\end{array}$ & $\boldsymbol{t}$-test & $\boldsymbol{p}$ \\
\hline Comprehensibility & $27.56 \pm 5.31$ & $30.16 \pm 3.24$ & -3.72 & $<.005$ \\
\hline Meaningfulness & $14.58 \pm 2.32$ & $21.65 \pm 2.81$ & -17.24 & $<.0001$ \\
\hline Manageability & $19.39 \pm 3.29$ & $27.51 \pm 1.47$ & -20.03 & $<.0001$ \\
\hline Total values means sum & $61.53 \pm 3.64$ & $79.23 \pm 2.65$ & -34.94 & $<.0001$ \\
\hline
\end{tabular}

Table 3. Correlation coefficients between the factors

\begin{tabular}{|c|c|c|c|c|c|c|c|c|c|c|c|}
\hline No. & Factors & 1 & 2 & 3 & 4 & 5 & 6 & 7 & 8 & 9 & 10 \\
\hline 1. & Ashamed of the body shape & 1 & $.432 *$ & .289 & .228 & $.568^{*}$ & $.461 *$ & .216 & .095 & .289 & 0.229 \\
\hline 2. & Fear to become fat & $.432 *$ & & $.387^{*}$ & $.491 *$ & $.521 *$ & $.712 *$ & .215 & .098 & .186 & .168 \\
\hline 3. & $\begin{array}{l}\text { Dissatisfaction with the body } \\
\text { shape compared with other } \\
\text { women }\end{array}$ & .289 & .387 & 1 & $.584 *$ & $.589 *$ & $.724 *$ & $.412 *$ & .067 & .193 & .192 \\
\hline 4. & $\begin{array}{l}\text { Efforts to change the body } \\
\text { shape }\end{array}$ & .228 & $.491^{*}$ & $.584 *$ & 1 & $.567 *$ & $.694^{*}$ & .214 & .211 & .297 &. $.443 *$ \\
\hline 5. & $\begin{array}{l}\text { Negative emotions about the } \\
\text { body shape }\end{array}$ & $.568^{*}$ & $.521^{*}$ & $.589^{*}$ & $.567^{*}$ & 1 & $.689 *$ & $.521^{*}$ & $.681^{*}$ & $.521^{*}$ & $.374 *$ \\
\hline 6. & $\begin{array}{l}\text { Dissatisfaction with the body } \\
\text { shape }\end{array}$ & $.461^{*}$ & $.712 *$ & $.724 *$ & $.694 *$ & $.689 *$ & 1 & .252 & .193 & $.646^{*}$ & $.733^{*}$ \\
\hline 7. & Comprehensibility & .216 & .216 & $.412 *$ & .214 & $.521 *$ & .252 & 1 & $.425 *$ & $.714^{*}$ & $.483^{*}$ \\
\hline 8. & Meaningfulness & .095 & .098 & .067 & .111 & $.681 *$ & .193 & $.425 *$ & 1 & $.532 *$ & $.397 *$ \\
\hline 9. & Manageability & .289 & .186 & .193 & .197 & $.521 *$ & $.646^{*}$ & $.714 *$ & $.532 *$ & 1 & $.526^{*}$ \\
\hline 10. & Sense of coherence & .229 & .168 & .192 & $.443 *$ & $.374^{*}$ & $.733^{*}$ & $.483 *$ & $.397 *$ & $.526^{*}$ & 1 \\
\hline
\end{tabular}

although the study results are conflicting. Thus, Bergeron and Tylka (2007) found a significant correlation between the boys' dissatisfaction with their bodies and their psychological well-being. However, in their study Bookwala and Boyar (2008) found that dissatisfaction of body level predicted poorer psychological well-being only for women. However, Ganem, Heer, and Morera (2009) observed that dissatisfaction of body predicted poor psychological well-being for both girls and boys.
Body dissatisfaction manifests over the whole period of life. It is believed (Hrabosky, Masheb, White, \& Grilo, 2007), that persons who are dissatisfied with their bodies overestimate this influence on their self-esteem as well.

Kater (2005) believes that body dissatisfaction is related to other people's approach and attitudes to the body, its beauty, diet and physical activity. It is believed (Greenleaf, 2005) that desired or 
perceived ideal body is highly dependent on the culture and society in which the person resides.

According to Mills, Fuller-Tyszkiewicz, and Holmes' (2014) research, body dissatisfaction predicted subsequent avoidance of social interactions. If women chose to avoid social interactions, their body dissatisfaction worsened, but when they did engage in active social interactions, their body satisfaction improved. In the study (Swami, Frederick, Aavik, \& Alcalay, 2010), covering 10 regions of the world, shows that the media exposure predicted body dissatisfaction among women and desire for thinness was commonplace in high socioeconomic-status across settings world regions.

Interesting data on body satisfaction was obtained in C. Markey and P. Markey's (2014) study. It revealed that lesbian women preferred larger body ideals than heterosexual women and that women's ideal body preferences were not related to their partners' weight status.

The changes of sense of coherence values in fitness classes reflect the findings presented in Table 2. The estimates for all three factors in the overall internal sense of coherence level changes were significant $(p<.05)$. Our study results on scale SOC-13 corresponded to the data of other researchers (Oosthuizen \& Van Lill, 2008 - the assessment that they used on the scale SOC-29). Lithuanian internal sense of coherence research was conducted by Javtokas (2009), but he used a very concise modified version of the SOC questionnaire preferred for mass analysis. Sense of coherence is a very important factor in human life because as stated by Strumpfer and De Bruin (2009), an individual with a strong sense of coherence will put efforts and energy into live demands and see them as challenges.

Correlation links were found between the set of derived factors. The strongest correlation was found between comprehensibility and manageability
(.814), body shape dissatisfaction and manageability (.746) and body shape dissatisfaction and sense of coherence (.833).

The relationships of the sense of coherence with most of the human condition indicators confirm the results of many researchers. Thus, the sense of coherence links with mental health was confirmed by Eriksson and Lindström (2006). Eriksson and Lindström (2007) analysed 32 articles that disclosed the relationship between the sense of coherence and the quality of live, which indicates that sense of coherence level predicts subjectively perceived level of the quality of live.

So, we have obtained results that are consistent with the findings of other researchers.

\section{CONCLUSION}

Systematic fitness training positively affects women's satisfaction with their body. We found a significant relationship between body shape dissatisfaction and the sense of coherence. The effect of physical activity improved all three components of the sense of coherence construct. The indicators as comprehensibility, meaningfulness and manageability show that respondents may already have better control of their sense of coherence.

Limitations and Direction for Future Research. First, a limitation in this study is that the sample was restricted to middle age women. Thus, it is unknown whether the results can be generalized to represent all women in Lithuania. Further research should be carried out with groups that are more representative of women and men. Second, the variables of interest in this study were restricted to women's body shape dissatisfaction and internal sense of coherence. In the future, researchers could extend our research design to examine other variables, such as the subjective quality of live, mental and physical health in relations with physical activity.

\section{REFERENCES}

Antonovsky, A. (1987). Unravelling the mystery of health. How people manage stress and stay well. San Francisco: Jossey-Bass.

Benas, J. S., \& Gibb, B. E. (2007). Peer victimization and depressive symptoms: The role of body dissatisfaction and self-esteem. Journal of Cognitive Psychotherapy: An International Quarterly, 21(2), 107-116.

Bergeron, D., \& Tylka, T. (2007). Support for the uniqueness of body dissatisfaction from drive for muscularity among men. Body Image, 4(3), 288-295. doi:10.1016/j.bodyim.2007.05.002

Bookwala, J., \& Boyar, J. (2008). Gender, excessive body weight, and psychological well-being in adulthood. Psychology of Women Quarterly, 32, 188-195. doi: 10.1111/j.1471-6402.2008.00423.x

Bothmer, von M., \& Fridlund, B. (2003). Self-rated health among university students in relation to sense of coherence and other personality traits. Scandinavian Journal of Caring Sciences, 17, 347-357. 
Brown, A., \& Dittmar, H. (2005). Think "thin" and feel bad: The role of appearance scheme activation, attention level, and thin-ideal internalisation for young women's responses to ultra-thin media ideals. Journal of Social and Clinical Psychology, 24(8), 1010-1035.

Choate, L. H. (2005). Towards a theoretical model of women's body image resilience. Journal of Counselling \& Development, 83, 320-329.

Cooper, P. J., Taylor, M. J., Cooper, Z., \& Fairburn, C. G. (1987). The development and validation of the body shape questionnaire. International Journal of Eating Disorders, 6(4), 485-494.

Dittmar, H. (2009). How do "body perfect" ideals in the media have a negative impact on body image and behaviours? Factors and Processes related to Self and Identity. Journal of Social and Clinical Psychology, 28(1), 1-8.

Dohnt, H. K., \& Tiggemann, M. (2006). Body image concerns in young girls: The role of peers and media prior to adolescence. Journal of Youth and Adolescence, 35(2), 141-151.

Engeln-Maddox, R. (2005). Cognitive response to idealized media images of women: The relationship of social comparison and critical processing to body image disturbance in college women. Journal of Social and Clinical Psychology, 4(8), 1114-1138. doi: 10.1521/ jscp.2005.24.8.1114

Eriksson, M., \& Lindström, B. (2007). Antonovsky’s sense of coherence scale and its relation with quality of life: A systematic review. Journal of Epidemiology and Community Health, 61(11), 938-944. doi: 10.1136/ jech.2006.056028

Eriksson, M., \& Lindström, B. (2006). Antonovsky's sense of coherence scale and the relation with health: A systematic review. Journal of Epidemiology and Community Health, 60(5), 376-381. doi: 10.1136/ jech.2005.041616

Eriksson, M., \& Lindström, B. (2005). Validity of Antonovsky's sense of coherence scale: A systematic review. Journal of Epidemiology and Community Health, 59, 460-466.

Fonseca, H., \& De Matos, M. G. (2005). Perception of overweight and obesity among Portuguese adolescents: An overview of associated factors. European Journal of Public Health, 15(3), 323-328.

Ganem, P. A., Heer, H., \& Morera, O. F. (2009). Does body dissatisfaction predict mental health outcomes in a sample of predominantly Hispanic college students? Personality \& Individual Differences, 46(4), 557-561. doi: 10.1016/j.paid.2008.12.014

Gianini, L. M., \& Smith, J. E. (2008). Body dissatisfaction mediates the relationship between selfesteem and restrained eating in female undergraduates. International Journal of Behavioral Consultation and Therapy, 4(1), 48-59. doi: EJ861335

Gilbert-Diamond, D., Baylin, A., Mora-Plazas, M., \& Villamor, E. (2009). Correlates of obesity and body image in Colombian women. Journal of Women's Health, 18(9), 1145-1157. doi: 10.1089/jwh.2008.1179
Greenleaf, C. (2005). Self-objectification among physically active women. Sex Role, 52(1/2), 51-62. doi: 10.1007/s11199-005-1193-8

Hambleton, R. K., Merenda, P., \& Spielberger, C. (Eds.). (2005). Adapting educational and psychological tests for cross-cultural assessment. Mahwah, NJ: Erlbaum.

Hrabosky, J. I., Masheb, R. M., White, M. A., \& Grilo, C. M. (2007). Overvaluation of shape and weight in Binge Eating Disorder. Journal of Consulting and Clinical Psychology, 75(1), 175-80. doi: 10.1037/0021843X.117.2.414

Javtokas, Z. (2009). Sveikatos stiprinimo konspektas. Vilnius. Retrieved from http://smlpc.lt/media/file/ Skyriu_info/Kvalifikacijos_tobulinimas/Lektura/Sveikatos_stiprinimas-Konspektas2.pdf

Kalimo, R., Pahkin, K., Mutanen, P., Alcalay, L., \& Topipinen-Tanner, S. (2003). Staying well or burning out at work: Work characteristics and personal resources as long-term predictors. Work Stress, 17(2), 109-122. doi: 10.1080/0267837031000149919

Kater, K. J. (2005). About Body Image Health. Retrieved from www.bodyimagehealth.org/about.html

Markey, Ch. N., \& Markey, P. M. (2014). Gender, sexual orientation, and romantic partner influence on body image: An examination of heterosexual and lesbian women and their partners. Journal of Social and Personal Relationships, 31, 162-177. doi: 10.1177/0265407513489472

McLaren, L., \& Kuh, D. (2004). Body dissatisfaction in midlife women. Journal of Women \& Aging, 16(1), 35-54. doi: 10.1300/J074v16n01_04

McPherson, K. E., \& Turnbull, J. D. (2005). Body image satisfaction in scottish men and its implications for promoting healthy behaviors. International Journal of Men's Health, 4(1), 3-12.

Meland, E., Haugland, S., \& Breidablik, H. (2007). Body image and perceived health in adolescence. Health Education Research, 22(3), 342-350. PMID: 16957015

Mills, J., Fuller-Tyszkiewicz, M., \& Holmes, M. (2014). State body dissatisfaction and social interactions: An experience sampling study. Psychology of Women Quarterly, 1(38), 551-562. doi: 10.1177/0361684314521139

Oosthuizen, J. D., Van Lill, B. (2008). Coping with stress in workplace. South African Journal of Industrial Psychology, 34(1), 64-69. doi: 10.4102/sajhrm.v8i1.247

Pasha, G., \& Golshekoh, F. (2009). Relationship between socio cultural attitudes, appearance and body dissatisfaction among students of Islamic Azad University. Journal of Applied Sciences, 9, 1726-1732. doi: 10.3923/jas.2009.1726.1732

Paxton, S. (2007). Friendship, body image and dieting in teenage girls: A research report. National Eating Disorder Information Centre. Retrieved from www. nedic.ca.

Pomerleau, C. S., \& Saules, K. (2007). Body image, body satisfaction, and eating patterns in normal- weight and overweight/obese women current smokers and never- 
smokers. Addictive Behaviors, 32(10), 2329-2334. doi: 10.1016/j.addbeh.2007.01.027

Presnell, K., Bearman, S. K., \& Madeley, M. C. (2007). Body dissatisfaction in adolescent females and males: Risk and resilience. The Prevention Researcher, 14(3), 3-6.

Skirka, N. (2000). The relationship of hardiness, sense of coherence, sports participation, and gender to perceived stress and psychological symptoms among college students. The Journal of Sports Medicine and Physical Fitness, 40, 63-70.

Strumpfer, D. J., \& De Bruin, G. P. (2009). Antonovsky’s sense of coherence and job satisfaction: Meta-analyses of South African data. South African Journal of
Industrial Psychology, 35(1), 172-174. doi: 10.4102/ sajip.v35i1.767

Sujoldzic, A., \& De Lucia, A. (2007). A crosscultural study of adolescents - BMI, body image and psychological well-being. Collegium Antropologicum, 31(1), 123-130.

Svami, V., Frederick, D. A., Aavik, L., \& Alcalay, L. (2010). The attractive female body weight and female body dissatisfaction in 26 countries across 10 world regions: Results of the International Body Project I. Personality and Social Psychology Bulletin, 36(3), 309 325. doi: 10.1177/0146167209359702

Šivert, Š., \& Sinanovic, O. (2008). Body dissatisfactionis age a factor? Philosophy, Sociology, Psychology and History, 7(1), 55-61. doi: 159.923.2-055.2(497.15) 